\title{
Optimization of Spelt Pasta Composition, Regarding Inulin Hpx Content and Eggs Quantity
}

\author{
Jelena Filipović ${ }^{1}$, Lato Pezo ${ }^{2}$, Nada Filipović ${ }^{1}$, Vladimir Filipovici ${ }^{1, *}$, Jovana Brkljača ${ }^{1}$, Aleksandra Jevtić- \\ Vukmirović ${ }^{3}$ \\ ${ }^{1}$ University of Novi Sad, Institute for Food Technology, Bul. Cara Lazara 1, 21000 Novi Sad, Serbia \\ ${ }^{2}$ University of Belgrade, Institute of General and Physical Chemistry, Studentski Trg 12 - 16, 11000 Beograd, Serbia \\ ${ }^{3}$ High Agricultural food School of Professional Studies, Ćirila i Metodija 1, 18400 Prokuplje, Serbia \\ *Corresponding author: vladaf@uns.ac.rs
}

Received March 13, 2014; Revised April 30, 2014; Accepted May 09, 2014

\begin{abstract}
This paper investigates the effect of inulin (0, 5 and 10\%) and liquid egg quantity $(0,124$ and $248 \mathrm{~g} / \mathrm{kg}$, equal to 0,3 and 6 eggs respectively) on the technological quality of spelt pasta to obtain new products with altered nutritional properties. Post-hoc Tukey's HSD test at 95\% confidence limit showed significant differences between various samples. Standard score analysis is applied for accessing the contribution of eggs and inulin content to spelt pasta quality. Maximum score (0.75) for explaining nutritive (protein, lipids, carbohydrates), textural and colour characteristics are experienced with pasta having $248 \mathrm{~g} / \mathrm{kg}$ eggs and $5 \%$ inulin content, while pasta with $10 \%$ of inulin and no eggs showed the worst score result $(0.25)$. Egg quantity strongly influence texture properties (maximum values obtained were: $4087.15 \mathrm{~g}$ for hardness, with $248 \mathrm{~g} / \mathrm{kg}$ eggs and no inulin; $6.37 \mathrm{gsec}$, for adhesiveness, with $10 \%$ inulin and no eggs added; 18.30 gsec for toughness with $124 \mathrm{~g} / \mathrm{kg}$ eggs and no inulin). Inulin showed influence on pasta colour (maximum values have been observed with $248 \mathrm{~g} / \mathrm{kg}$ eggs and $10 \%$ inulin content). Statistical analysis point at the versatile beneficial contributions of eggs in whole meal spelt pasta enriched with inulin enabling the optimization of pasta dough formula.
\end{abstract}

Keywords: inulin HPX, eggs, spelt pasta, quality, statistical analysis

Cite This Article: Jelena Filipović, Lato Pezo, Nada Filipović, Vladimir Filipović, Jovana Brkljača, and Aleksandra Jevtić-Vukmirović, "Optimization of Spelt Pasta Composition, Regarding Inulin Hpx Content and Eggs Quantity.” Journal of Food and Nutrition Research, vol. 2, no. 4 (2014): 167-173. doi: 10.12691/jfnr-2-4-6.

\section{Introduction}

Dietary fibre ingredients are added into conventional pasta to increase its health benefits. Dietary fibre functions are mostly recognized as potential health benefit like prevention of constipation, reduction of bowel transit time and reduction in the risk of colorectal cancer, lowering of blood cholesterol and regulation of blood glucose levels for diabetes management [1]. The results of Veläzquez's study [2] indicated that the main by-products of microbial fermentation of dietary fibre and oligosaccharides are short-chain fatty acid (SCFA). Dietary fibre is a prebiotic that stimulates the growth of beneficial gut micro flora. Inulin is a naturally occurring storage polysaccharide found in many plants such as onion, garlic, artichoke and chicory. Inulin, as a glucofructan, consists of a mixture of oligomers and polymers containing 2 to $60 \beta 2$-1 linked D - fructose molecules. Inulin is a dietary fibre and it is not hydrolyzed by the endogenous secretion of human digestive enzymes. Its ability to function as a fat or sugar replacer without adversely impacting food flavour is highlighted [3-8].

The nutritive value of spelt wheat is high and superior compared to Triticum aestivum non-starch carbohydrates, proteins, lipids, vitamins, cellulose and mineral elements (Fe, $\mathrm{Zn}, \mathrm{Cu}, \mathrm{Mg}$ and P) [9,10,11]. Adding inulin to spelt pasta may be a suitable strategy to increase its nutritional value compared to conventional pasta by enhancing prebiotic function. Interest in inulin in pasta has increased due to important functional properties, physiological functions (eventually preventing diseases occurrence) and its technological importance. The dynamic way of life has the tendency to simplify and decrease a way of preparing healthy, quick, cheap, safe organic meals and pasta is meeting these goals $[5,6,13,14,15,16]$.

This paper investigates the effect of inulin $(0,5$ and $10 \%)$ and liquid egg quantity $(0,124$ and $248 \mathrm{~g} / \mathrm{kg}$, equal to 0,3 and 6 eggs) on the technological quality of spelt pasta to obtain new products with improved nutritional properties. In order to enable more comprehensive comparison between investigated samples, particularly the contribution of egg quantity and inulin content, standard score (SS), assigning equal weight to all assays applied, has been used. Simple regression models, using Response Surface Methodology (RSM) and second order polynomial models (SOP) were proposed for calculation of nutritive quality, textural properties and colour attributes as function of the egg quantity and inulin content. 


\section{Material and Methods}

\subsection{Material}

For pasta production, whole meal spelt flour grown in the year 2011 in Serbia with the characteristics of moiture content of $13.3 \%$, ash content of $2.4 \%$, sugar, protein, cellulose, starch and lipids contens of 4.39, 15.9, 2.5, 56.6 and $2.4 \%$ respectively, was used. Inulin HPX, white powder, characterized by an average degree of polymerization of more than 10 sugar units. It is insoluble fiber a commercial product from the root of Jerusalem artichoke, produced by "ORAFTI Active Food Ingredients”, Belgium.

\subsection{Chemical Analyses of Wholemeal Spelt Flour and Pasta}

Basic chemical analyses (protein, starch, lipid, sugar, ash, cellulose and moisture) whole meal spelt flour and pasta were determined according to official methods of AOAC [17].

\subsection{Preparation of pasta}

Pasta was made using the device "La Parmigiana D45" MAC 60. In a paddle mixer whole meal moisture was adjusted to $31.5 \%$ by adding water, inulin HPX and liquid eggs. Liquid eggs were first mixed into a homogeneous mass. Whole meal spelt flour, was replaced by inulin HPX in the quantity $0 \%, 5 \%$ or $10 \%$ and applied quantity of eggs was 0,124 or $248 \mathrm{~g} / \mathrm{kg}$ (equivalent to 0,3 or 6 eggs class D, respectively). Homogeneous hydrated whole meal with no large lumps entered an extrusion worm which moved the loose dough forward and simultaneously compress it into a homogeneous plastic mass prior to extrusion through a die with $1.4 \mathrm{~mm}$ diameter used for spaghetti. Mixing time was 15 min [18]. Raw pasta was dried in a cabinet drier for about 12 hours at controlled temperature that did not exceed $45 \mathrm{C}$ and $70 \%$ until pasta reached the moisture around $12.5 \%$, followed by cooling to $25^{\circ} \mathrm{C}$, $50 \mathrm{rh}$ for $4 \mathrm{~h}$ and then stored at room temperature in sealed containers. Drying conditions and air flow were stringently controlled to avoid creating a discontinuity in the moisture gradient between the interior and exterior of spaghetti.

\subsection{Pasta Quality- Texture Analysis}

Textural properties of cooked pasta were measured with Texture analyzer TA. HD plus (Stable Micro System, U.K.) equipped with a 5-kg load cell. The preparation procedure was the same for all tested samples (duration of cooking, time period between cooking and testing). Hardness and adhesiveness of cooked pasta were measured using a $36 \mathrm{~mm}$ cylinder probe (P/36R) (instrument settings were as follows, mode: measure force in compression, pre-test speed: $2.0 \mathrm{~mm} \mathrm{sec}^{-1}$; test-speed: 1 mm sec ${ }^{-1}$; post-test speed: $10 \mathrm{~mm} \mathrm{sec}^{-1}$; strain: 75\%; trigger force: $5 \mathrm{~g}$ ). The maximum force correlates to the hardness of the sample. Adhesiveness is calculated from the negative areas of the plots. Toughness (area under the force/time curve) was measured using the WarnerBratzler shear blade (type HDP/BS) and the following settings: pre-test speed: $2 \mathrm{~mm} \mathrm{sec}^{-1}$; test-speed: $2 \mathrm{~mm}$ $\mathrm{sec}^{-1}$; post-test speed: $10 \mathrm{~mm} \mathrm{sec}^{-1}$; distance: $15.00 \mathrm{~mm}$; trigger force: $10 \mathrm{~g}$. The tests were performed on 10 replicates per batch. The two spaghetti strands were held close together and positioned centrally under the probe during testing.

\subsection{Pasta Colour}

Pasta colour $\left(\mathrm{L}^{*}\right.$ - lightness, $\mathrm{b}^{*}$ - share of yellow colour if positive value and blue colour if negative value, $C^{*}$ differences in colouration) was measured by objectively colourimeter Chroma meter (CR-400, Konica, Minolta, Japan) and was determined according to the procedure described by Filipović et al., [19].

\subsection{Statistical Analyses}

The experimental data used for the study of experimental results were obtained using a $3^{2}$ full factorial experimental design (3 level-2 parameter), with 9 runs (1 block), according to Response surface methodology, Mišljenović, [20]. It was used to design tests for nutritive quality, textural properties and colour attributes, considering two factors: quantity of eggs $(0,124$ and 248 $\mathrm{g} / \mathrm{kg}$, equal to 0,3 and 6 eggs, respectively), and inulin content (0, 5 and 10\%).

The following SOP model was fitted to the experimental data. Eleven models of the following form were developed to relate four responses $(Y)$ and two process variables $(X)$ :

$$
\begin{aligned}
& Y_{k}=\beta_{k 0}+\sum_{i=1}^{2} \beta_{k i} \cdot X_{i} \\
& +\sum_{i=1}^{2} \beta_{k i i} \cdot X_{i}^{2}+\beta_{k 12} \cdot X_{1} \cdot X_{2}, \\
& k=1-11 .
\end{aligned}
$$

where: $\beta_{k 0}, \beta_{k \mathrm{i}}, \beta_{k \mathrm{ii}}, \quad \beta_{k 12}$ are constant regression coefficients; $Y_{k}$, either specific nutritive quality, or textural properties or colour attributes; $X_{1}$ quantity of eggs; $X_{2}$ inulin content.

Descriptive statistical analyses for all the obtained results were expressed as the mean \pm standard deviation (SD). Analysis of variance (ANOVA) has been utilized to show relations between applied assays. Principal component analysis (PCA), used as pattern recognition technique, has been applied within assay descriptors to characterize and differentiate various analysed samples. The evaluation of one-way ANOVA and PCA analyses of the obtained results were performed using StatSoft Statistica $10.0 \AA$ software. Applied methodology was the same as described before [19].

\subsection{Determination of normalized standard scores (SS)}

Standard scores is one of the most widely used technique to compare various characteristics of complex food samples determined using multiple measurements, where samples are ranked based on the ratio of raw data and extreme values of the measurement used. Since the units and the scale of the data from various nutritive, textural and colour characteristics measuring methods are different, the data in each data set should be transformed 
into normalized scores, dimensionless quantity derived by subtracting the minimum value from the raw data, and divided by the subtract of maximum and minimum value, according to following equations:

$$
\bar{x}_{i}=1-\frac{\max _{i} x_{i}-x_{i}}{\max _{i} x_{i}-\min _{i} x_{i}}, \quad \forall i
$$

in case of "the higher, the better" criteria, or

$$
\bar{x}_{i}=\frac{\max _{i} x_{i}-x_{i}}{\max _{i} x_{i}-\min _{i} x_{i}}, \quad \forall i
$$

in case of "the lower, the better" criteria, where $x_{i}$ represents the raw data. The normalized scores of a sample for different measurements when averaged give a single unitless value termed as SS, which is a specific combination of data from different measuring methods with no unit limitation. This approach also enables the ease of employing some others set of pasta formulations to this elaboration.

Standard scores for different samples investigated in this article were calculated and the result has been written to Table 3.

\begin{tabular}{|c|c|c|c|c|c|c|c|c|}
\hline \multirow{2}{*}{ Pasta } & \multirow{2}{*}{ Quantity of eggs (g/kg) } & \multirow{2}{*}{ Quantity of inulin (\%) } & \multicolumn{5}{|c|}{ Content (\% d.m.) } & \multirow{2}{*}{ SS } \\
\hline & & & Protein & Starch & Cellulose & Sugars & Lipids & \\
\hline TS1 & 0 & 0 & $15.87 \pm 0.21^{\mathrm{bcd}}$ & $56.49 \pm 0.39^{c}$ & $2.11 \pm 0.04^{b}$ & $2.42 \pm 0.02^{c}$ & $2.70 \pm 0.02^{\mathrm{e}}$ & 0.31 \\
\hline TS2 & 0 & 5 & $15.53 \pm 0.13^{\mathrm{b}}$ & $53.67 \pm 0.57^{\mathrm{b}}$ & $2.70 \pm 0.04^{\mathrm{a}}$ & $2.53 \pm 0.02^{\text {abd }}$ & $2.54 \pm 0.07^{\mathrm{a}}$ & 0.38 \\
\hline TS3 & 0 & 10 & $14.56 \pm 0.10^{\mathrm{e}}$ & $51.53 \pm 0.89^{\mathrm{ab}}$ & $2.68 \pm 0.05^{\mathrm{a}}$ & $2.55 \pm 0.02^{\mathrm{ab}}$ & $2.42 \pm 0.07^{\mathrm{a}}$ & 0.25 \\
\hline TS4 & 124 & 0 & $17.16 \pm 0.33^{\mathrm{a}}$ & $56.15 \pm 1.41^{\mathrm{c}}$ & $1.97 \pm 0.03^{\mathrm{e}}$ & $2.47 \pm 0.04^{\mathrm{acd}}$ & $3.54 \pm 0.03^{f}$ & 0.57 \\
\hline TS5 & 124 & 5 & $16.47 \pm 0.15^{\mathrm{acd}}$ & $52.48 \pm 0.87^{\mathrm{ab}}$ & $2.19 \pm 0.04^{\mathrm{bc}}$ & $2.56 \pm 0.04^{\mathrm{ab}}$ & $3.81 \pm 0.05^{\mathrm{b}}$ & 0.50 \\
\hline TS6 & 124 & 10 & $15.78 \pm 0.12^{\mathrm{bc}}$ & $50.38 \pm 0.56^{\mathrm{a}}$ & $2.33 \pm 0.05^{\mathrm{d}}$ & $2.54 \pm 0.04^{\mathrm{ab}}$ & $3.84 \pm 0.05^{\mathrm{b}}$ & 0.47 \\
\hline TS7 & 248 & 0 & $18.12 \pm 0.41^{\mathrm{f}}$ & $52.44 \pm 0.35^{\mathrm{ab}}$ & $2.23 \pm 0.03^{\text {cd }}$ & $2.44 \pm 0.04^{\mathrm{cd}}$ & $4.69 \pm 0.08^{\mathrm{d}}$ & 0.71 \\
\hline TS8 & 248 & 5 & $17.20 \pm 0.36^{\mathrm{a}}$ & $50.61 \pm 1.08^{\mathrm{a}}$ & $2.94 \pm 0.01^{\mathrm{f}}$ & $2.56 \pm 0.04^{\mathrm{ab}}$ & $4.56 \pm 0.04^{\mathrm{c}}$ & 0.75 \\
\hline TS 9 & 248 & 10 & $16.57 \pm 0.21^{\mathrm{ad}}$ & $47.55 \pm 0.96^{\mathrm{d}}$ & $2.63 \pm 0.02^{\mathrm{a}}$ & $2.63 \pm 0.04^{b}$ & $4.58 \pm 0.03^{\mathrm{cd}}$ & 0.67 \\
\hline $\mathrm{CV}$ & & & 2.26 & 2.51 & 2.05 & 1.64 & 2.83 & \\
\hline Polarity & & & + & + & + & + & + & \\
\hline
\end{tabular}

Table 1. Mean values of the nutritive composition of pasta from different formulation

${ }_{\mathrm{a}, \mathrm{b}, \mathrm{c}, \mathrm{d}}$ Different letters printed in superscript within the same column show significantly different means of observed data (at $\mathrm{p}<0.05$ level, according to post-hoc Tukey's HSD test), CV - coefficient of variation

Polarity: ' + ' = the higher the better criteria, ' - ' = the lower the better criteria

Table 2. Textural properties and colour attributes of pasta from different formulation

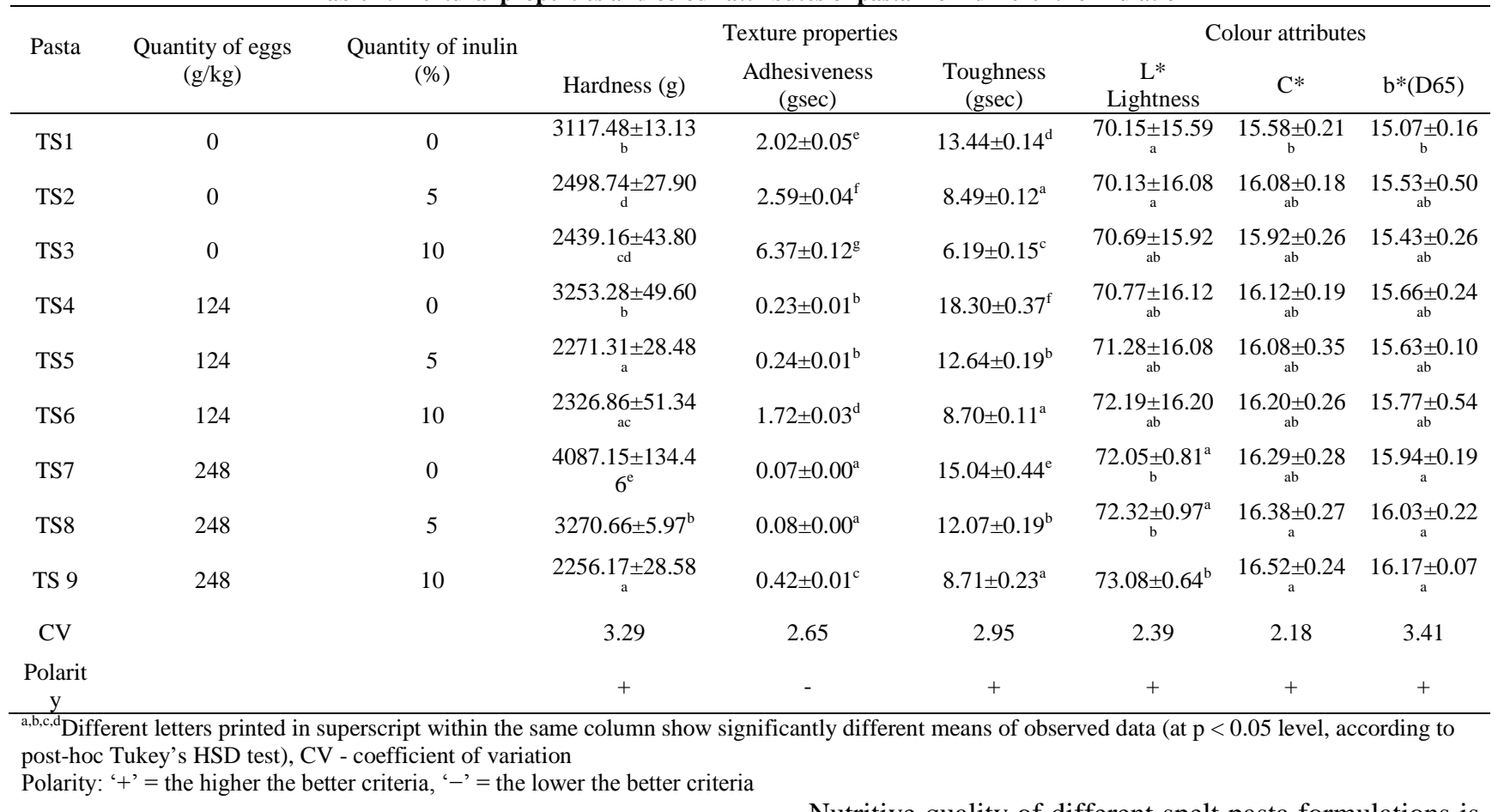

\section{Results and Discussion}

\subsection{Quality of Whole Meal Spelt Pasta with Inulin and Eggs}

ANOVA and the following post-hoc Tukey's HSD test were evaluated for comparison of nutritive composition data, textural properties and colour attributes for different formulation of pasta.
Nutritive quality of different spelt pasta formulations is presented in Table 1 . Statistically significant differences were found in almost all samples of pastas. Low coefficients of variation have been obtained for each applied assay (1.64-2.83\%), which confirmed the high precision of the measurements and statistically significant results. Investigated pastas are characterized by high crude protein content, and as expected, protein content increases with the quantity of eggs added to formulation statistically significant, at $\mathrm{p}<0.05$ level). 
Spelt whole meal flour alone is characterized by high protein content (Table 1), qualifying this raw material as suitable for pasta production. Starch content for pastas with 10 and 5\% inulin decrease due to inulin replacement $(p<0.05)$ according to Table 2 . Higher cellulose content is seen with increased eggs quantity and inulin content, the highest value has been observed with 5\% inulin and 248 $\mathrm{g} / \mathrm{kg}$ eggs. Sugar content increases with the rise of inulin share and with the increase in quantity of eggs. The highest value was encountered with $10 \%$ inulin and $248 \mathrm{~g} / \mathrm{kg}$ eggs, (Table 1). According to Coussment [21] commercial inulin powers is typically sugars and oligosaccharides. As expected, quantity of added eggs is influencing lipid content $(\mathrm{p}<0.05)$, due to the egg yolk which contains 31-35\% lipids [22].

The textural quality of cooked pasta is considered as critical characteristic in evaluating the overall quality of pasta. The textural characteristics of pasta play an essential role in determining the final acceptance by consumers [13]. Textural properties of pasta from different formulations were also found to be statistically different for almost all samples of pastas (Table 2). Low coefficients of variation have been obtained for each applied assay (2.18-3.41\%). Inulin content reduces hardness $(p<0.05)$ due to protein dilution, which is consistent with data reported by Aravind et al., (2012 a, b). Hardness of pastas is generally increased with the quantity of added eggs due to the positive influence of egg proteins and lipids on the gluten matrix [23]. Highest value has been observed for pasta with $248 \mathrm{~g} / \mathrm{kg}$ eggs and with no inulin addition and the lowest for sample with 3 eggs and $5 \%$ inulin indicating that the quantity of eggs has to be increased. Pasta hardness increased with increasing protein level, actually quantity of eggs due to the higher number of polypeptide chains associated with higher protein levels which have fortified protein matrix. Toughness of pastas is positively influenced by the quantity of eggs (best results has been observed with 124 $\mathrm{g} / \mathrm{kg}$ ) and it is reduced by increasing the inulin content $(\mathrm{p}<0.05)$. Our results are similar to results which were obtained by Raina et al., [24], who claimed that the mean value for toughness of raw pasta increased with increasing the protein level. Adhesiveness of pastas is decreased with the quantity of eggs, and increased with inulin content. Adhesiveness trends can be explained by the physicochemical nature of inulin. Inulin hydrates more quickly than the starch and protein components of flour, in turn leading to starch and fibre fractions of the pasta being less incorporated in a matrix. If the starch is not encapsulated within a protein matrix cooking it may form a sticky layer at the surface of the product, resulting in higher levels of adhesiveness [13,15,25]. The texture properties of spelt pasta containing inulins are improved by additopn of eggs.

Eggs were traditionally included in pasta dough. Eggs confer a nice yellow colour, superior taste, firmer structure and more elastic texture of final product. Depending on the origin, dietary fibres contribute to pasta colour. Due to the share of spelt bran layer, colour attributes are not found statistically different for all whole meal pasta samples with inulin. Observed statistically significant differences were found between some samples with no and maximum added eggs to formulation emphasizing the positive influence of egg yolk.

\subsection{PCA and Standard Scores Analsis of Spelt Pasta Quality}

The PCA allows a considerable reduction in a number of variables and the detection of structure in the relationship between measuring parameters [26] and different samples of spelt pasta formulations that give complimentary information. The full auto scaled data matrix consisting of spelt pasta with 0,124 and $248 \mathrm{~g} / \mathrm{kg}$ eggs and 0,5 and $10 \%$ inulin content formulations were submitted to PCA.

For visualizing the data trends and the discriminating efficiency of the used descriptors a scatter plot of samples using the first two principal components (PCs) from PCA of the data matrix is obtained (Figure 1). As can be seen, there is a neat separation of the nine samples of spelt pasta formulations, according to nutritive quality, textural properties and colour attributes. Quality results show that the first two principal components, account for $86.60 \%$ of the total variability and can be considered sufficient for data representation and for nutritive quality, textural properties and colour attributes. Concerning nutritive quality, textural properties and colour attributes, colour coordinates were the dominant variables in the first principle component, while the toughness and hardness of pasta were the most dominant variables in the second principle component.

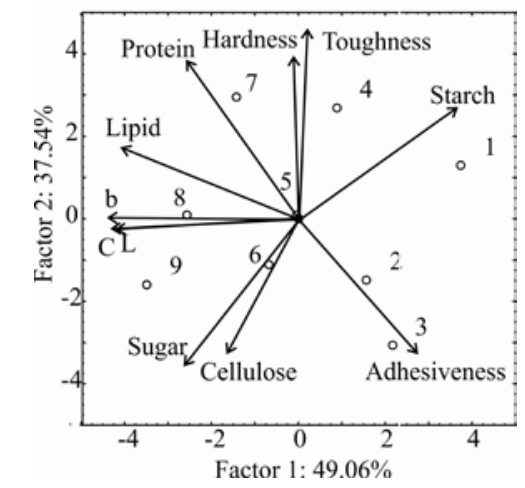

Figure 1. Biplot diagram of spelt pasta composition, regarding inulin HPX content and eggs quantity

Standard Scares, SS as the mean value of standard score transformed from the initial data generated with different methods for each sample were calculated by assigning each measured parameter equal weight. In this integrated approach SS is in a numerical, unitless scale value. Although it is a relative index and may not represent a specific property of different samples, previous experience with other samples [19] proved that SS provides a reasonably accurate rank of spelt pasta. In this article, standard scores are calculated for nutritive, texture and colouring properties and obtained data were presented in Table 4. A score above 0.5 stands for a high standard in nutritive, texture and colour characteristics. That is, Spelt pasta properties with Score above 0.5 show more competitive qualities compared to other pastas. This mans that the addition of eggs or the addition of more inulin content to formulations with Score values below 0.5 would improve quality characteristics.

Using the standard score analysis for different spelt pasta formulations can not only realize their position regarding other formulations, but also have a reference for 
developing strategies to improve their characteristics. The best scores are calculated for pasta with more eggs added, while inulin was not so influential for the final Score. The best standard score (0.75) on nutritive composition of pasta is with $248 \mathrm{~g} / \mathrm{kg}$ eggs and $5 \%$ inulin.

Table 3. Standard scores of pasta from different formulation

\begin{tabular}{cccc}
\hline \multirow{2}{*}{ Pasta } & Quantity of eggs (g/kg) & Quantity of inulin (\%) & $\begin{array}{c}\text { Standard scores } \\
\text { SS }\end{array}$ \\
\hline TS1 & 0 & 0 & 0.31 \\
TS2 & 0 & 5 & 0.38 \\
TS3 & 0 & 10 & 0.25 \\
TS4 & 124 & 0 & 0.57 \\
TS5 & 124 & 5 & 0.50 \\
TS6 & 124 & 10 & 0.47 \\
TS7 & 248 & 0 & 0.71 \\
TS8 & 248 & 5 & 0.75 \\
TS 9 & 248 & 10 & 0.67 \\
\hline
\end{tabular}

\subsection{ANOVA and RSM Calculation}

ANOVA calculation for nutritive composition of analyzed pastas (Table 4) revealed the significant effects of independent variables, quantity of eggs and inulin content. The SOP models for all variables were found to be statistically significant and the response surfaces were fitted to these models. The linear terms were found significant $(\mathrm{p}<0.05)$ for protein and starch content SOP models and their influence was found to be the most important in model calculations. The quantity of eggs was found to be the most dominant variable for the protein content mode, while inulin content was the most influential in the starch content model. Cellulose content was most affected by inulin content (both linear and quadratic terms were statistically significant at $\mathrm{p}<0.05$ level). Inulin content was found as most influential variable for sugar content, while lipid content was mostly influenced by egg quantity.

Table 4 shows that all SOP models had insignificant lack of fit tests, which mean that all the models represented the data satisfactorily. Coefficients of determinations $\left(\mathrm{r}^{2}\right)$ also expressed high accuracy of developed mathematical models, reaching values between 0.906 and 0.986 .

ANOVA calculation for textural properties and colour attributes of pasta from different formulation reveals that the hardness of pasta is mostly influenced by linear term of inulin content, statistically significant at $\mathrm{p}<0.05$ level (Table 4), reaching higher values with lesser inulin content, while adhesiveness is more influenced by the quantity of eggs, reaching higher values with lesser eggs content. Variable interaction term was also statistically significant in adhesiveness calculation. Toughness is mostly influenced by inulin content, but the quadratic term of eggs quantity was also statistically significant. Eggs quantity statistically terms influence the colour attributes, statistically significant at $\mathrm{p}<0.05$ level. Inulin content has been found statistically significant in lightness calculation, at $\mathrm{p}<0.05$ level.

Table 4. ANOVA calculation for nutritive composition, textural properties and colour attributes of pasta from different formulations

\begin{tabular}{ccccccc|ccccccc}
\hline \multicolumn{7}{c}{ Nutritive composition } & \multicolumn{6}{c|}{ Textural properties and colour attributes } \\
\hline & $\mathrm{dF}$ & Protein & Starch & Cellulose & Sugar & Lipid & dF & Hardness & Adhesiveness & Toughness & $\mathrm{L}^{*}$ & $\mathrm{C}^{*}$ & $\mathrm{~b}^{*}$ \\
\hline Egg quantity & 1 & $5.867^{*}$ & $20.468^{*}$ & 0.015 & 0.003 & $6.339^{*}$ & 1 & $404872^{* *}$ & $18.099^{*}$ & $9.876^{* *}$ & $6.985^{*}$ & $0.430^{*}$ & $0.738^{*}$ \\
Egg $^{2}$ quantity & 1 & 0.053 & $1.828^{* *}$ & $0.295^{*}$ & 0.000 & 0.044 & 1 & 214835 & $2.865^{* *}$ & $13.087^{*}$ & 0.000 & 0.000 & 0.000 \\
Inulin & 1 & $2.969^{*}$ & $40.649^{*}$ & $0.292^{*}$ & $0.025^{*}$ & 0.001 & 1 & $1967368^{*}$ & $6.368^{*}$ & $89.580^{*}$ & $1.494^{*}$ & 0.069 & 0.082 \\
Inulin $^{2}$ & 1 & 0.006 & 0.057 & $0.165^{* *}$ & 0.004 & 0.000 & 1 & 108685 & 1.398 & 0.876 & 0.121 & 0.011 & 0.007 \\
Egg q x Inulin $^{1}$ & 1 & 0.014 & 0.001 & 0.007 & 0.001 & 0.008 & 1 & $332161^{* *}$ & $4.013^{*}$ & 0.213 & 0.061 & 0.003 & 0.004 \\
Error & 5 & 0.076 & 0.926 & 0.080 & 0.003 & 0.093 & 5 & 165281 & 0.952 & 3.442 & 0.136 & 0.079 & 0.064 \\
\hline $\mathrm{r}^{2}$ & & 0.991 & 0.986 & 0.906 & 0.918 & 0.986 & & 0.948 & 0.972 & 0.971 & 0.984 & 0.867 & 0.929 \\
\hline
\end{tabular}

${ }^{*}$ Significant at $\mathrm{p}<0.05$ level, ${ }^{* *}$ Significant at $\mathrm{p}<0.10$ level, $95 \%$ confidence limit

$\mathrm{dF}$ - degrees of freedom

Table 4 shows that all kinetics SOP models had insignificant lack of fit tests, which mean that all the models represented the data satisfactorily. $r^{2}$ values $(0.867$ - 0.972) showed high accuracy of developed mathematical models.

3D surface plots were drawn for experiment data visualization (white coloured points) and for the purpose of observation the fitting regression models to experimental data. Protein content varied with process variables, showing the higher values, with the increase of eggs quantity and the decrease of inulin content. Starch content, showed better results with lesser quantity of eggs and lower inulin content, while cellulose content reached the highest value with $5 \%$ of inulin. Sugar content had its maximum value with 6 eggs and $10 \%$ inulin content. Lipid content reached its maximum values with pastas having 6 eggs. Hardness is shown on Figure 2, minimum value has been observed with 3 eggs and $10 \%$ inulin, while the maximum hardness has been found to be with 6 eggs and no inulin content. Minimum adhesiveness has been observed with 6 eggs and 5\% inulin content Figure 3 ), while maximum adhesiveness has been observed with no eggs and $10 \%$ inulin content. Figure 4 shows the changes in toughness of different pasta formulation, the increase of this parameter is observed with lesser inulin content, and the best result was noticed with 3 eggs and no inuline. Colour changes have been also monitored, and according to results, lightness coordinate $\left(\mathrm{L}^{*}\right)$ is increased with the rise of both inulin content and the quantity of eggs. The same conclusion can be applied to colour coordinates $\mathrm{C}^{*}$ and $\mathrm{b}^{*}$.

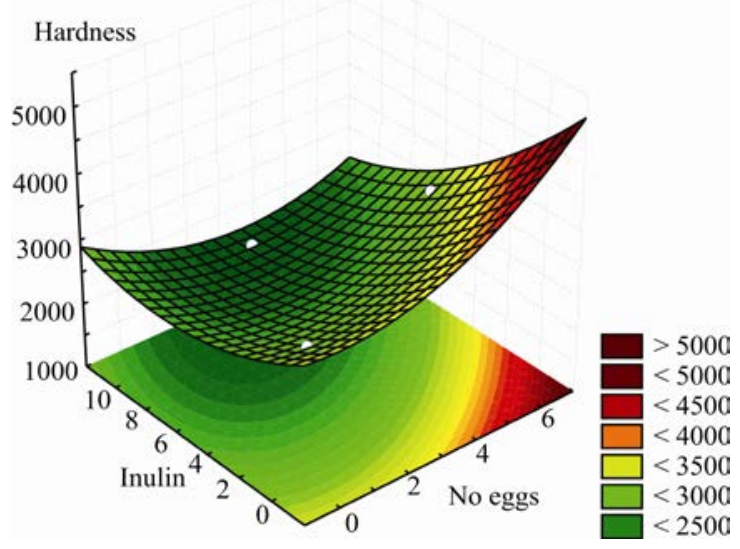

Figure 2. Hardness as and function of inulin content the quantity of eggs 


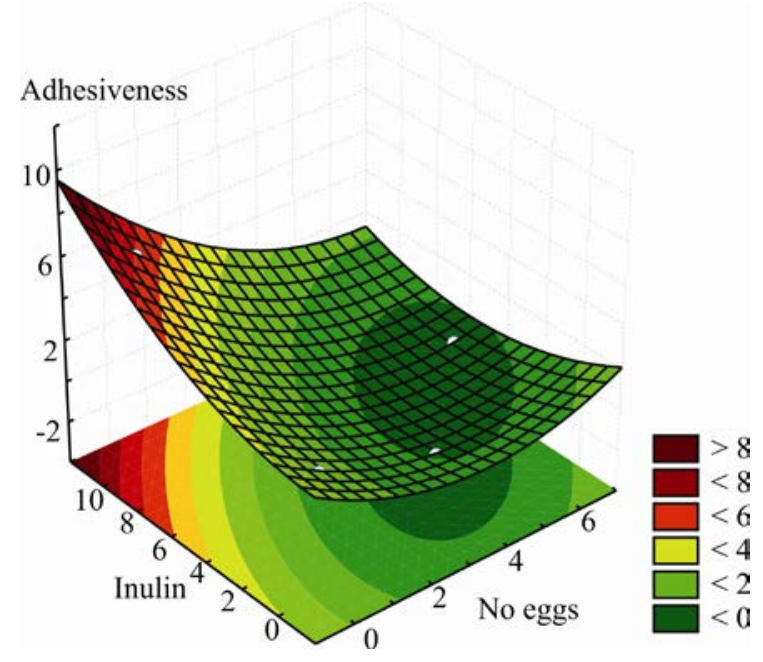

Figure 3. Adhesiveness as function of inulin content and the quantity of eggs

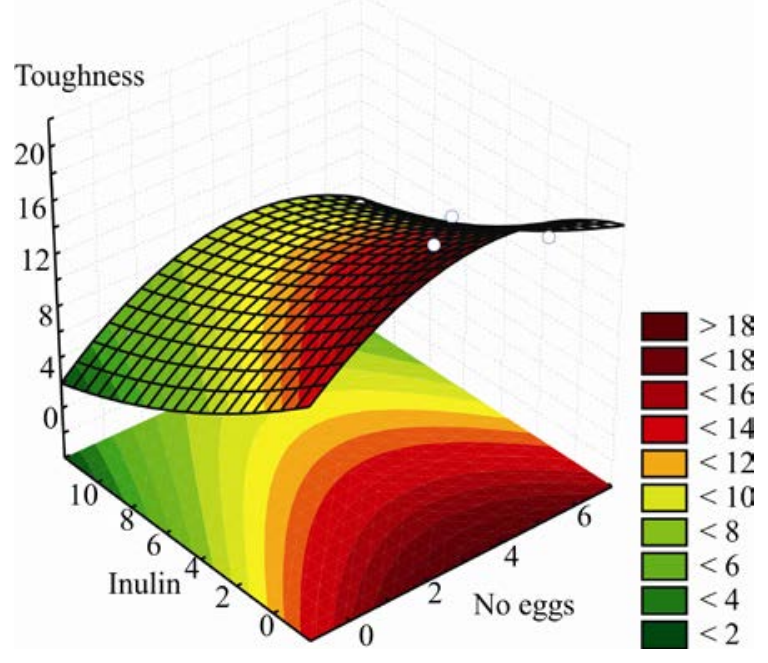

Figure 4. Toughness as function of inulin content and the quantity of eggs

\section{Conclusion}

Based on the presented data it can be concluded that:

The best standard scores are calculated for pasta with more eggs added, while inulin was not so influential.

Nutritive composition of pasta is dependent on egg quantity and inulin content, with maximum protein and lipid content measured with no inulin and 6 eggs added. Starch content is reduced with addition of both eggs and inulin, while maximum cellulose content was observed with $5 \%$ inulin content. Sugar content is strongly increased with addition of inulin.

Textural properties of pasta from different formulations reveals that the hardness of pasta is the highest with 6 eggs added and no inulin, while adhesiveness is the highest with $10 \%$ inulin content and no eggs added to the formulations. Toughness is the highest with 3 eggs added and no inulin in the formulation. The $\mathrm{L}^{*}, \mathrm{C}^{*}$, and $\mathrm{b}^{*}$ colour coordinates reached their maximum values with 6 eggs and $10 \%$ inulin added to pasta formulations.

On the whole, statistical analyses point at the versatile beneficial contributions of eggs in whole meal spelt pasta enriched with inulin enabling the optimization of pasta dough formula.

\section{Acknowledgements}

These results are part of the project supported by the Ministry of Education and Science of the Republic of Serbia, TRI 46005.

\section{Statement of Competing Interests}

The authors have no competing interests.

\section{List of Abbreviations}

SCFA - short-chain fatty acid, SS - standard score,

RSM - Response Surface Methodology, SOP - second order polynomial models, $r^{2}$ - Coefficients of determinations, $\mathrm{L}^{*}$ - lightness coordinate, $\mathrm{b}^{*}$ - share of yellow colour, $\mathrm{C}^{*}$-differences in colouration, SD - standard deviation, ANOVA - Analysis of variance, PCA - Principal component analysis, PC - principal components,

\section{References}

[1] Brennan, C. and Cleary, L., "The potential use of cereal $(1 \rightarrow 3$, $1 \rightarrow 4)-\beta$-D-glucans as functional food ingredients", Review, Journal of Cereal Science, 42. 1-13. 2005.

[2] Veläzquez, M., Davies, C., Marret, R., Slavin, J. L. and Feirtag, J.M. "Effect of oligosaccharides and fibre substitutes on shortchain fatty acid production by human microflora", Anaerobe, 6 . 87-92. 2000.

[3] Tungland, B., "A call for dietary fibre status for inulin", Cereal Foods World, 45 (9). 413-413. 2000.

[4] Roberfroid, M. B., "Introducing Inulin-Type Fructans", British Journal of Nutrition, 93. 13- 25. 2005.

[5] Filipović, J., Popov, S., Filipović, N., "Behavior of different fibres at bread dough freezing", Chemical Industry \& Chemical Engineering Quarterly, 14 (4). 257-259. 2008.

[6] Filipović, J., Filipović, N., "Fibres in the dough influencing freezing and thawing kinetics", International journal of food science and technology, 45 (1). 1-6. 2010.

[7] Filipović, J., Filipović, N., Filipović, V., "The effects of commercial fibres on frozen bread dough", Journal of the Serbian Chemical Society, 75 (2). 195-207. 2010.

[8] Elleuch, M., Bedigian, D., Roiseux, O., Besbes, S., Blecker, C., "Dietary fibre and fibre-rich by products of food processing: Characterization, technological functionality and commercial applications": A review, Food Chemistry, 124. 411-421. 2011.

[9] Bojanska, T., Frančakova, H., "The use of spelt wheat (Triticum spelt L.) for baking applications", Rostilinna Vyroba, 48 (4). 141147. 2002.

[10] Marconi, E., Carcea, M., Schiavine, M., Cubadda, R., "Spelt (Tritucum spelt L) pasta quality: combined effect of flour properties and drying conditions", Cereal Chemistry. 79. 634-639. 2002.

[11] Abdel-Aal, E-S. M., El-Sayed, M., Rabalsk, I., "Effect of baking on nutrition properties of starch in organic spelt whole grain products", Food Chemistry, 111, 150-156. 2008.

[12] Beirão-da-Costa, L.M., Januário M.I.N., Leitão A.E. B., Simão F.M.L.S., "Characterization of inulin from chicory and salsify cultivated in Portugal", $4^{\text {th }}$ Mercosur Congress on Process Systems Engineering, Rio de Janeiro, Brazil, 11-18. 2005.

[13] Tudorică, C., Kuri, V., Brennan, C.,"Nutritional and physicochemical characteristics of dietary fibre enriched pasta", Journal of agricultural and food chemistry, 50. 347-356. 2002. 
[14] Filipović, N., Filipović, J., Filipović, V., Popov, S., Psodorov, Đ., "Mathematical modeling the kinetics of freezing/thawing of the bread dough with fibres", Romanian Biotechnological letters, 17, (3), 7330-7339. 2012.

[15] Aravind, N., Sissons, M., Egan N., Fellows, C., "Effect of insoluble dietary fibre addition on technological, sensory and structural properties of durum wheat spaghetti", Food Chemistry, 130, 299-309. 2012.

[16] Mastromatteo, M., Iannetti, M., Civica, V., Sepielli G., Alessandro, Del Nobile M., "Effect of the Inulin Addition on the Properties of Gluten Free Pasta", Food and Nutrition Sciences, 3. 22-27. 2012.

[17] AOAC. Official methods of analysis. 17 ed. Washington> Association of Official Analytical Chemists. 2000.

[18] Kaludjerski, G., Filipović, N., Methods for the investigation of cereals, flour and final product quality,. Faculty of Technology, Novi Sad, 71-118. 1998.

[19] Filipović, J., Pezo, L., Filipović, N., Filipović, V., BodrožaSolarov, M., Plančak, M. "Mathematical approach to assessing spelt cultivars (Triticum aestivum subsp. spelt) for pasta making", International Journal of food science and technology, 48 (1). 195203. 2013.

[20] Mišljenović, N., Koprivica, G., Pezo, L., Lević, Lj., Ćurčić, B., Filipović, V., Nićetin, M., "Optimization of the osmotic dehydration of carrot cubes in sugar beet molasses", Thermal science, 16 (1), 43-52. 2012.

[21] Coussement, P., "Inulin and Oligofructose: Safe Intakes and Legal Status", Journal of Nutrition, 129 (7). 1412-1417. 1999.

[22] Jurić, V., Jajić, I., Bursić V., Jurić J., "Usability and nutritive value of eggs", Chronicle of scientific papers, 1. 138-145. 2005.

[23] Khouryieh, H., Herald, T., Aramouni, F., "Quality and Sensory Properties of Fresh Egg Noodles Formulated with Either Total or Partial Replacement of Egg Substitutes", Journal of Food Science, 71 (6). 433-437. 2006.

[24] Raina, C.S., Singh, S., Bawa, A.S., Saxena, D.C., "Textural Characteristics of Pasta Made From Rice Flour Supplemented With Proteins And Hydrocolloids", Journal of Texture Studies, 36. 402-420. 2006.

[25] Aravind, N., Sissons, M., Fellows, C., Blazek, J., Gilbert, E. "Effect of inulin soluble dietary fibre addition on technological, sensory and structural properties of durum wheat spaghetti", Food Chemistry, 132. 993-1002. 2012.

[26] Ansari, R., Kazi, T.G., Jamali, M.K., Arain, M.B., Wagan, M.D. Jalbani, N., Afridi, H.I., Shah, A.Q., "Variation in accumulation of heavy metals in different verities of sunflower seed oil with the aid of multivariate technique", Food Chemistry, 115 (1). 318-323. 2009. 